\title{
Resource-oriented therapeutic models in psychiatry: conceptual review
}

\author{
Stefan Priebe, Serif Omer, Domenico Giacco and Mike Slade
}

\section{Background}

Like other medical specialties, psychiatry has traditionally sought to develop treatments targeted at ameliorating a deficit of the patient. However, there are different therapeutic models that focus on utilising patients' personal and social resources instead of ameliorating presumed deficits. A synopsis of such models might help to guide further research and improve therapeutic interventions.

\section{Aims \\ To conduct a conceptual review of resource-oriented therapeutic models in psychiatry, in order to identify their shared characteristics.}

\section{Method}

The literature was searched to identify a range of resourceoriented therapeutic models, particularly for patients with severe mental illness. Key texts for each model were analysed using a narrative approach to synthesise the concepts and their characteristics.

\section{Results}

Ten models were included: befriending, client-centred therapy, creative music therapy, open dialogue, peer support workers, positive psychotherapy, self-help groups, solutionfocused therapy, systemic family therapy and therapeutic communities. Six types of resources were utilised: social relationships, patients' decision-making ability, experiential knowledge, patients' individual strengths, recreational activities and self-actualising tendencies. Social relationships are a key resource in all the models, including relationships with professionals, peers, friends and family. Two relationship dimensions - reciprocity and expertise - differed across the models.

\section{Conclusions}

The review suggests that a range of different therapeutic models in psychiatry address resources rather than deficits. In various ways, they all utilise social relationships to induce therapeutic change. A better understanding of how social relationships affect mental health may inform the development and application of resource-oriented approaches.

\section{Declaration of interest}

None.
Medical diseases are commonly characterised by a deficit, and treatments are designed to target - directly or indirectly - that deficit, so that the patient is cured or at least not hindered by the deficit any more. The history of psychiatry has been dominated by a similar deficit focus. ${ }^{1,2}$ Treatments have been developed to remove or ameliorate the presumed deficit, even if assumptions on the specific nature of the deficits may often have been rather speculative. Such a deficit focus applies to models of pharmacological treatments as well as psychotherapeutic ones, such as psychoanalysis or cognitive-behavioural therapy, that aim to solve an underlying conflict or to change maladaptive thinking and behaviours. This focus on deficits has a number of limitations $;{ }^{2-4}$ for example, it may strengthen a negative image of patients ${ }^{4}$ and reduce their sense of control, leaving them passive recipients of expert care. ${ }^{2}$ Arguably more important is that the deficit focus in psychiatric research has produced, at best, limited progress in developing more effective treatments since the 1980s. ${ }^{5,6}$ New perspectives might help to advance treatments and develop novel and more effective ones. Not all therapeutic models in psychiatry, however, have been developed to target deficits. Instead, a number of very different models of therapeutic interventions aim to tap into the strengths of patients and utilise their positive personal and social resources. Such models can be considered as 'resource-oriented'. Eventually they may indirectly affect the symptoms of a defined disease, but their primary target is patients' resources rather than deficits. Resource-oriented models have been described by a large body of literature and have been more or less widely used in practice. In the literature they are usually treated separately without considering their shared resource orientation. A synoptic view of resource-oriented models with an analysis of their commonalities and differences might help to specify how resources may be used in psychiatric treatment, guide further research on effective ways of using resources therapeutically and support the development of more beneficial interventions in the future.

Against this background we conducted a conceptual review of resource-oriented therapeutic models in psychiatry. The review focused on therapeutic models for patients with severe mental illness, as the traditional core group of patients in psychiatry, without using diagnostic categories. Conventional diagnostic categories, sometimes linked to the idea of disorder-specific treatments, may suggest a more deficit-oriented understanding of disease which would have been inconsistent with the aim of the review. Our specific objectives were to compile a non-exhaustive list of distinct therapeutic models in psychiatry that can be seen as resource-oriented and to identify their key characteristics.

\section{Method}

A systematic search with fixed search terms was of limited use as the resource orientation of such models has not necessarily been explicitly addressed in the literature, and the sources of such information are often disparate. Instead, we followed the recommendations for conceptual reviews by Lilford et al to gain a diverse understanding of resource-oriented models. ${ }^{7}$ This included:

(a) searching widely using disparate databases and sources, i.e. journal articles, textbooks and internet-based sources within a variety of disciplines, without attempting an exhaustive review of all the literature;

(b) making sure that the review is informed by different perspectives; 
(c) allowing some overlap in the various stages of the review process so that the precise nature and scope of the review can be clarified.

To achieve the different perspectives as set out in the second recommendation, our review team was multidisciplinary and included two academic/clinical psychiatrists (S.P., who is also a psychologist, and D.G.), an academic/clinical psychologist (M.S.) and a research psychologist (S.O.). They were trained and qualified in three different countries (Germany, Italy and the UK), represented different age groups and possessed different areas of expertise. Moreover, the emerging findings were regularly discussed by a team of about 20 researchers and clinicians in East London.

\section{Data collection}

We did not aim to compile an exhaustive list of all models that might be seen as resource-oriented, but to compile a diverse sample of distinct models. We started by identifying a range of models from the literature known to the authors and complemented this with a general search of PsycINFO, Medline and Google Scholar (any date) using keywords such as "resources" or "resource-oriented" or "resource-based" or "strengths" or "strength-based" or "strengths-oriented" AND "therapy" or "psychotherapy" or "interventions". Reference lists of relevant papers were also screened. The inclusion criteria for the models were: first, that the original model focused primarily on utilising patients' resources rather than ameliorating a deficit; second, that the models were implemented in practice with individuals with severe mental illness; third, they were explicitly described in the literature (as a defined model) and established in practice in more than one service (so as to exclude descriptions of models that were either never or only experimentally implemented); and fourth, were sufficiently distinct from each other to allow for the analysis of aspects across different models. As we were interested in conceptual characteristics, we did not consider evidence for effectiveness.

For each of the identified models we conducted a nonsystematic search of PsycINFO, Medline and Google Scholar using the names of the models as keywords (e.g. "client-centred therapy" OR "solution-focused therapy"). Results and relevant reference lists were screened for key texts describing each model. Such key texts included the original description of the model, commonly cited standard publications, textbooks and guidelines from professional bodies. Again, we did not aim to compile an exhaustive list of texts for each model, but to gain a sufficient conceptual understanding of each model for the purpose of the review.

\section{Data analysis}

We used a two-stage narrative synthesis approach modified from the guidelines set out by Popay et al. ${ }^{8}$ In line with Lilford et al, ${ }^{7}$ these stages had some overlap. Continuous discussion among the multidisciplinary team, critical reflection and feedback from other researchers and clinicians were used throughout. In the first stage an initial framework of criteria was developed with which to explore the commonalities and differences. Key texts were read and a list of criteria was generated to characterise the resources used in the models. This was achieved through an inductive process, whereby understanding the descriptions of the models in the key texts led to the formulation of the criteria, and through continuous discussion among the research team to refine the criteria in an iterative process. In the second stage, key texts were re-read and each model was characterised based on the framework of criteria using tabulation. The extent to which each model met these criteria was based on the explicit descriptions of the models in the key texts. Commonalities and differences were then analysed and the focus of the review decided accordingly. These characteristics were continuously discussed among the research team in an iterative process.

\section{Results}

\section{Resource-oriented models of therapeutic intervention}

We identified ten distinct resource-oriented therapeutic models to be included in the further analysis.

\section{Befriending}

Befriending schemes involve the regular provision of a supportive relationship through one-to-one companionship, by matching volunteers with patients who engage in shared social and recreational activities. ${ }^{9-12}$

\section{Client-centred therapy}

Client-centred therapy assumes that all people have a self-actualising tendency. It facilitates this self-determination towards optimal functioning through helpful therapist behaviour with empathy, congruence and unconditional regard. ${ }^{13-17}$

\section{Creative music therapy}

The Nordoff-Robbins model of music therapy uses music creation and the meaningful interactions within it to encourage patients' personal growth, expressive skills and ability to relate to others. ${ }^{18-22}$

\section{Open dialogue}

Open dialogue treats patients within their own personal support systems. This is achieved by involving patients, their social network and healthcare professionals in joint treatment meetings and promoting a dialogue to help them understand the patients' experiences. $^{23-25}$

\section{Peer support workers}

Peer support workers are individuals with a history of mental illness who are employed in the provision of care of others with similar problems. ${ }^{26,27}$

\section{Positive psychotherapy}

Positive psychotherapy uses a number of exercises to build happiness by encouraging positive attitudes, cognitions and behaviours. ${ }^{28}$

\section{Self-help groups}

In self-help groups or mutual support groups, people with shared problems meet regularly to support one another. ${ }^{29-31}$

\section{Solution-focused therapy}

Solution-focused therapy helps patients identify exceptions to the problem and then find possible solutions that work independently of the cause of the problem. ${ }^{32-34}$

\section{Systemic family therapy}

Systemic family therapy can include different structural and strategic models. ${ }^{35-38}$ They all treat patients within the context of the family, focusing on interactions or boundaries to mobilise the family's resources.

\section{Therapeutic communities}

Therapeutic communities aim to create a community within an institution. They provide a 'living-learning' situation, in which 
everything that occurs between staff and patients can be applied to life outside. ${ }^{39-42}$

\section{Resource-oriented themes}

The two-stage synthesis identified six themes describing different types of resources that are explicitly utilised and developed in the models. The themes have some overlap, but still represent different criteria to characterise the models. Table 1 summarises their distribution across the different models.

\section{Social relationships}

All ten models utilise the patients' social relationships in one way or another. As a result, this later became the focus of further analyses in the review.

\section{Patients' decision-making abilities}

Several models rely on the patient's decision-making ability. In client-centred therapy the therapist takes a non-directive approach, allowing patients to make their own decisions. ${ }^{13-17}$ Similarly, in solution-focused therapy the patient is seen as the expert who knows which solutions would work best. The therapist asks the right questions to guide the patient in identifying these solutions. ${ }^{32-34}$ Creative music therapy also allows patients to have a high level of freedom in deciding where to go next with the session and in what way they wish to contribute to the session. ${ }^{18-22}$ In the open dialogue model the patient's opinion on treatment decisions is important, even if this means holding back on medication or hospitalisation. $^{24,25}$ Finally, in therapeutic communities, shared decision-making among both patients and staff is an important principle. $^{39,40}$ These models all show confidence that the patients know best and utilise their ability to make decisions.

\section{Experiential knowledge}

Some of these models utilise the experience and knowledge of the patient. In solution-focused therapy the patient is encouraged to think of what has worked in the past, to identify potential solutions. ${ }^{32-34}$ In therapeutic communities it is hoped that the experiences of the patients within the community provide skills and knowledge that can be applied to life outside the institution. ${ }^{39-41}$ Similarly, in positive psychotherapy the three good blessings' exercise requires the patient to write down three good things that have happened and why. ${ }^{28}$ Another exercise also involves 'savouring' something that patients normally rush in everyday life and writing down what they did differently and how it felt. These exercises can encourage the use of patients' experiential knowledge. Self-help groups and peer support workers, on the other hand, utilise the experience of patients in helping others who are going through a similar situation. ${ }^{26,27,29,31}$ Experiential knowledge is, therefore, a resource that can be drawn upon either to help the individual directly or to help others who share the problem.

\section{Patients' individual strengths}

Some of these models also use the individual strengths of patients, i.e. what it is that they are good at. In positive psychotherapy this is achieved through the 'signature strengths' exercise in which patients write down their top five strengths and think of ways that they could use these within everyday life. ${ }^{28}$ In solution-focused therapy the therapist helps patients to explore the things that work. This may involve the identification of strengths that could be drawn upon as a solution. ${ }^{32-34}$ Finally, in creative music therapy the patients' strengths are used to structure the intervention itself. For example, if patients are good at singing, writing music or playing an instrument, then this should be utilised in the session. ${ }^{18-22}$ The patients' individual strengths are a key resource that can be drawn upon both to achieve the aims of an intervention and to guide the intervention itself.

\section{Recreational activities}

Three of the models use recreational activities. Many self-help groups provide an opportunity for patients to engage in recreational and social activities together. ${ }^{29}$ In creative music therapy patients are given the opportunity to play instruments, write music or sing. ${ }^{18-22}$ A key aspect of befriending involves the befriender and the person befriended taking part in various recreational activities together, such as going to the cinema, playing sports and socialising. ${ }^{9-12}$ These recreational activities can be used to build confidence and meaningful contact with others.

\section{Self-actualising/self-correcting tendencies}

Finally, two of the models also share the assumption that individuals or groups have natural positive tendencies that can be utilised. In client-centred therapy it is assumed that all humans have a self-actualising tendency, a drive to be the best they can be. ${ }^{13,15}$ It taps into this drive within individuals to grow and simply provides the right environment for such growth to occur. Similarly, systemic family therapy utilises the family's natural homoeostatic mechanisms and self-actualising tendency. For example, in structural family therapy the therapist might challenge the balance of the system, allowing it to correct itself favourably. ${ }^{35}$ Client-centred therapy and systemic family therapy have

\begin{tabular}{|c|c|c|c|c|c|c|}
\hline & $\begin{array}{c}\text { Social } \\
\text { relationships }\end{array}$ & $\begin{array}{c}\text { Patient's } \\
\text { decision-making } \\
\text { ability }\end{array}$ & $\begin{array}{l}\text { Experiential } \\
\text { knowledge }\end{array}$ & $\begin{array}{l}\text { Patient's } \\
\text { individual } \\
\text { strengths }\end{array}$ & $\begin{array}{c}\text { Recreational } \\
\text { activities }\end{array}$ & $\begin{array}{l}\text { Self-actualising/ } \\
\text { self-correcting } \\
\text { tendencies }\end{array}$ \\
\hline Befriending & Yes & & & & Yes & \\
\hline Client-centred therapy & Yes & Yes & & & & Yes \\
\hline Creative music therapy & Yes & Yes & & Yes & Yes & \\
\hline Open dialogue & Yes & Yes & & & & \\
\hline Peer support workers & Yes & & Yes & & & \\
\hline Positive psychotherapy & Yes & & Yes & Yes & & \\
\hline Self-help groups & Yes & & Yes & & Yes & \\
\hline Solution-focused therapy & Yes & Yes & Yes & Yes & & \\
\hline Systemic family therapy & Yes & & & & & Yes \\
\hline Therapeutic communities & Yes & Yes & Yes & & & \\
\hline
\end{tabular}


confidence in these natural positive tendencies and use them as a resource.

\section{Types of relationships}

As all ten resource-oriented models utilise relationships, we conducted further analyses to identify the types (with whom) and nature (how) of the relationships used. Four types of relationships are used: with professionals, peers, friends and family. Table 2 shows which types of relationships are used in the different models.

\section{Professionals}

Relationships between professionals and patients are a component explicitly used across the models. In client-centred therapy the patient's perception of empathy and unconditional positive regard from the therapist and the genuine contact between two individuals are central principles. ${ }^{13-17}$ Although an empathic therapeutic relationship can be seen as important in any psychological intervention, the client-centred model explicitly details it as the core element. Similarly, the therapeutic alliance and use of a solution-focused conversation between therapist and patient have been identified as specific active ingredients in solution-focused therapy. ${ }^{34}$ The professional-patient relationship is also central in therapeutic communities, where patients and staff are encouraged to take part in various shared everyday activities as learning experiences. ${ }^{41,42}$ Structured meetings also provide an opportunity to discuss any issues that may be affecting this community life to strengthen the relationships. ${ }^{42}$ Creative music therapy uses musical activities to engage patients in meaningful contact with a therapist, ${ }^{18-22}$ using non-verbal means for patients who might otherwise find it difficult to engage in such relationships. In open dialogue the principle of psychological continuity is important, in which the same professionals are involved in the patient's treatment meetings throughout to stay connected with the patient. ${ }^{24,25}$

\section{Peers}

Some of the models also utilise the patient's relationships with peers. In therapeutic communities this is similar to how relationships with professionals are utilised, i.e. through joint activities and structured meetings. ${ }^{41,42}$ Such relationships can be used as learning experiences to apply to relationships outside the institution. Self-help groups and peer support workers provide an opportunity for patients to gain social support from peers who have been through similar experiences and can offer additional empathy and understanding which a professional without such experience cannot. ${ }^{26,27,31}$ Finally, creative music therapy can provide meaningful contact with peers through non-verbal interactions in group sessions, ${ }^{18-22}$ which may benefit patients who are unable to engage in social relationships through other means.

Friends

The models also use friendships. In positive psychotherapy there are several therapeutic exercises that can improve a patient's friendships. ${ }^{28}$ 'Gratitude visits' stipulate that the patient should thank somebody to whom they are grateful. 'Active-constructive responding' involves reacting in a visibly positive and enthusiastic way to good news from someone else once a day. Such exercises encourage patients to appreciate their friendships and may strengthen them. Befriending schemes provide patients with new friendships, offering additional support and fostering their social skills. ${ }^{9-12}$ Finally, open dialogue mobilises a patient's wider social network from the start of their treatment. It attempts to create a dialogue to help significant members of the patient's social network, including friends, to have a better understanding of the patient's experiences. ${ }^{23-25}$

Family

The models also make use of the patient's family relationships. Systemic family therapy aims to improve the interactions and clarify the boundaries in the family system. ${ }^{35-38}$ This can mobilise the resources of the family to support a patient and build up resilience. Similarly, solution-focused therapy originally grew from family therapy to mobilise the resources of the family. ${ }^{43}$ Positive psychotherapy may utilise the family in the same way as it utilises friendships, through 'gratitude visits' and 'active-constructive responding. ${ }^{28}$ The open dialogue approach can also utilise the family in the same way as it does friendships, through creating a dialogue between the patient and family members. ${ }^{23-25}$

\section{Nature of relationships}

Whereas all the models utilise social relationships, their nature may vary in terms of the reciprocity of the helping relationship and the reliance of expertise.

\section{Reciprocity}

Some of the models suggest a reciprocal helping relationship between a therapeutic provider and the patient. In therapeutic communities both patients and staff should be seen as equal in the community, learning from one another and making decisions together. ${ }^{39-42}$ Similarly, self-help groups are usually run by the members of the groups themselves with everyone bringing their own support for one another. ${ }^{26}$ Befriending can also be seen as a reciprocal relationship in that both patient and befriender are there to create and maintain a friendship, not a therapeutic relationship. $^{9-12}$ Open dialogue also facilitates reciprocal

\begin{tabular}{|c|c|c|c|c|}
\hline & Professionals & Peers & Friends & Family \\
\hline Befriending & & & Yes & \\
\hline Client-centred therapy & Yes & & & \\
\hline Creative music therapy & Yes & Yes & & \\
\hline Open dialogue & Yes & & Yes & Yes \\
\hline Peer support workers & & Yes & & \\
\hline Positive psychotherapy & & & Yes & Yes \\
\hline Self-help groups & & Yes & & \\
\hline Solution-focused therapy & Yes & & & Yes \\
\hline Systemic family therapy & & & & Yes \\
\hline Therapeutic communities & Yes & Yes & & \\
\hline
\end{tabular}


relationships by promoting a dialogue to facilitate change in the whole family, ${ }^{23-25}$ and viewing patients as partners in therapy rather than objects of therapy. ${ }^{24}$ On the other hand, client-centred therapy, systemic family therapy, solution-focused therapy, creative music therapy, positive psychotherapy and peer support workers all suggest a unidirectional relationship with a therapeutic provider from whom a patient receives help. Peer support workers, however, may suggest a more reciprocal relationship than the others. $^{26}$

\section{Expertise}

There are some differences between the models in terms of who is seen as the expert. In client-centred therapy, ${ }^{13-17}$ solution-focused therapy, ${ }^{32-34}$ positive psychotherapy ${ }^{28}$ and open dialogue, ${ }^{23-25}$ the patient can be seen as the expert who knows best. The therapist taps into this expertise by asking relevant questions or providing necessary exercises. For self-help groups and peer support workers, ${ }^{26,27,29-31}$ it is the peers who have at least some of the relevant expertise. Their experience is relied on in supporting the patient. In therapeutic communities everyone can be seen as an expert and everyone is there to learn from each other. ${ }^{39-42}$ Patients are commonly seen as the experts, whether it be the patients themselves or peers. The only arguable exception to this is systemic family therapy, where the therapist can be seen as the expert who is there to influence the family system. ${ }^{35-38}$

\section{Discussion}

Using a narrative approach we synthesised conceptual characteristics of distinct resource-oriented therapeutic models for patients with severe mental illness and identified six resources that are utilised in such models: social relationships, patients' decision-making abilities, experiential knowledge, patients' individual strengths, recreational activities and self-actualising/correcting tendencies. Social relationships especially appear to be central in all the models. Further analysis identified four types of social relationships that may be used, i.e. with professionals, peers, friends and family. The nature of the relationships suggests a unidirectional helping relationship for most of the models, although some appear to be more reciprocal. Finally, the majority of the models suggest the expertise lies with the patients, either the patient in question or peers who have had similar experiences.

\section{Social relationships}

Although the review included very different models, all of them share one core characteristic - the idea of utilising social relationships to bring about change and help the patient. Relationships are also seen as important in other therapeutic models that do not primarily focus on resources, ${ }^{44,45}$ and have been suggested as crucial for the recovery process. ${ }^{46-49}$ However, people with severe mental illness have few close relationships to utilise. ${ }^{50-54}$ The therapeutic context may therefore be an approach to help the patient learn to establish and maintain beneficial relationships. Nevertheless, it has been suggested that some relationships may have a negative impact on a patient's recovery. ${ }^{47,55,56}$ Thus, the therapeutic task is not only to increase the number of social relationships, but also to help the patient to shape them so that they are beneficial. The models in this review vary in their explicit assumptions about how exactly relationships are to be used and benefit the patient, but two potentially important aspects were identified. Some, but not all, of the models provide a sense of reciprocity and expertise within the relationships. This may strengthen a person's sense of personal agency and efficacy, with a positive impact on their recovery. ${ }^{47,48,53,57}$ This importance of social relationships in psychiatric therapeutic models parallels similar trends towards emphasising relationships in other fields, including teacherstudent relationships in education, ${ }^{58}$ caregiver-child relationships in healthy child development, ${ }^{59}$ and helping relationships in social work and physical health. ${ }^{60,61}$

\section{Strengths and limitations}

Although we searched widely and included different perspectives, the reliance on expertise within the research team may have made the review and analysis selective. The findings represent the interpretation of the research team, may be influenced by their belief in the importance of a social dimension of mental healthcare, ${ }^{6}$ and do not constitute an exhaustive understanding of resource-oriented models in psychiatry. The characterisation of some models may also be seen as simplified and debatable. Finally, we focused only on resource orientation without exploring how such an approach may be integrated with a deficit orientation. However, the flexible and dynamic approach enabled us to gain a diverse understanding of the disparate literature, to conceptualise resource-oriented therapeutic models and to arrive at criteria for characterising key aspects.

\section{Implications of the study}

A number of therapeutic models in psychiatry do not target a deficit of the patient, but focus on the patient's positive resources. They vary, and are often rather vague, in the extent to which they specify which resources are used, how exactly they are mobilised and what precisely their beneficial effect is. More conceptual work on this might benefit from considering several models rather than analysing each one in isolation. All the models utilise social relationships, although the type and nature of the relationships vary. A better understanding of how social relationships affect patients' mental health might help to advance such models and, possibly, to develop new ones. This might require more specific theories about the helpful factors across social relationships and how they can be used in different therapeutic contexts. ${ }^{44,62}$ The identification of overarching aspects of relationships - such as reciprocity and expertise - might provide a framework for evaluating how different forms of relationships facilitate change and reduce mental distress.

In treatment studies, relationships and interactions should be assessed more systematically to provide evidence on helpful processes, and underpin the advancement of existing models and the development of novel ones. Further empirical research on social relationships is badly needed in psychiatry, and may inform the development of new therapeutic models in the future.

Stefan Priebe, FRCPsych, Serif Omer, BSC, Domenico Giacco, MD, Unit for Social and Community Psychiatry, Barts' and the London School of Medicine and Dentistry, Queen Mary College, University of London; Mike Slade, PhD, PsychD, Health Service and Population Research Department, King's College London, Institute of Psychiatry, London, UK

Correspondence: Professor Stefan Priebe, Unit for Social and Community Psychiatry, Newham Centre for Mental Health, London E13 8SP, UK. Email: s.priebe@qmul.ac.uk

First received 3 Apr 2013, final revision 5 Jul 2013, accepted 10 Oct 2013

\section{References}

1 Seligman ME, Csikszentmihalyi M. Positive psychology. An introduction. Am Psychol 2000; 55: 5-14.

2 Maddux JE, Snyder CR, Lopez SJ. Towards a positive clinical psychology: deconstructing the illness ideology and constructing an ideology of human strengths and potential. In Positive Psychology in Practice (eds PA Linley, S Joseph): 320-34. Wiley, 2004. 
3 Rashid T, Ostermann RF. Strength-based assessment in clinical practice. J Clin Psychol 2009; 65: 488-98.

4 Wright BA, Lopez SJ. Widening the diagnostic focus: a case for including human strengths and environmental resources. In Handbook of Positive Psychology (eds CR Snyder, SJ Lopez): 26-44. Oxford University Press, 2002.

5 Kleinman A. Rebalancing academic psychiatry: why it needs to happen - and soon. Br J Psychiatry 2012; 201: 421-2.

6 Priebe S, Burns T, Craig TKJ. The future of academic psychiatry may be social. Br J Psychiatry 2013; 202: 319-20.

7 Lilford RJ, Richardson A, Stevens A, Fitzpatrick R, Edwards S, Rock F, et al Issues in methodological research: perspectives from researchers and commissioners. Health Technol Assess 2001; 5: 1-57.

8 Popay J, Roberts H, Sowden A, Petticrew M, Arai L, Rodgers M, et al. Guidance on the Conduct of Narrative Synthesis in Systematic Reviews. University of Lancaster, 2006 (http://www.lancs.ac.uk/shm/research/nssr/ index.htm).

9 Kingdon DG, Turkington D, Collis J, Judd M. Befriending: cost-effective community care. Psychiatr Bull 1989; 13: 350-1.

10 McCorkle BH, Dunn EC, Wan YM, Gagne C. Compeer friends: a qualitative study of a volunteer friendship programme for people with serious mental illness. Int J Soc Psychiatry 2009; 55: 291-305.

11 Mitchel G, Pistrang N. Befriending for mental health problems: processes of helping. Psychol Psychother 2011; 84: 151-69.

12 Hallet C, Klug G, Lauber C, Priebe S. Volunteering in the care of people with severe mental illness: a systematic review. BMC Psychiatry 2012; 12: 226.

13 Rogers CR. Client-Centred Therapy: Its Current Practice, Implications and Theory. Constable, 1951.

14 Rogers CR. Counseling and Psychotherapy: Newer Concepts in Practice. Houghton Mifflin, 1942.

15 Rogers CR. On Becoming a Person: A Therapist's View of Psychotherapy. Houghton Mifflin, 1961.

16 Rogers $\mathrm{CR}$. The necessary and sufficient conditions of therapeutic personality change. J Consult Psychol 1957; 21: 95-103.

17 Rogers CR. Significant aspects of client-centered therapy. Am Psychol 1946 1: $415-22$

18 Nordoff $\mathrm{P}$, Robbins C. Therapy in Music for Handicapped Children. Barcelona Publishers, 2004

19 Nordoff P, Robbins C, Marcus D. Creative Music Therapy: A Guide to Fostering Clinical Musicianship. Barcelona Publishers, 2007.

20 Rolvsjord R. Resource-Oriented Music Therapy in Mental Health Care. Barcelona Publishers, 2010.

21 Ansdell G, Meehan J. 'Some light at the end of the tunnel': exploring users' evidence for the effectiveness of music therapy in adult mental health settings. Music Med 2010; 2: 29-40.

22 Procter S. Empowering and enabling: music therapy in non-medical mental health provision. In Contemporary Voices in Music Therapy: Communication Culture and Community (eds C Kenny, B Stige): 95-108. Unipub, 2002.

23 Seikkula J. Open dialogues with good and poor outcomes for psychotic crises: examples from families with violence. J Marital Fam Ther 2002; 28 263-74.

24 Seikkula J, Olson ME. The open dialogue approach to acute psychosis: its poetics and micropolitics. Fam Process 2003; 42: 403-18.

25 Seikkula J, Alakare B, Aaltonen J, Holma J, Rasinkangas A, Lehtinen V. Open dialogue approach: treatment principles and preliminary results of a two-year follow-up on first episode schizophrenia. Ethical Hum Sci Serv 2003 5: $163-82$.

26 Davidson L, Chinman M, Kloos B, Weingarten R, Stayner D, Tebes JK. Peer support among individuals with severe mental illness: a review of the evidence. Clin Psychol Sci Pr 1999; 6: 166-87.

27 Repper J, Carter T. A review of the literature on peer support in mental health services. J Ment Health 2011; 20: 392-411.

28 Seligman MEP, Rashid T, Parks AC. Positive psychotherapy. Am Psychol 2006; 61: 774-88.

29 Chinman M, Kloos B, O'Connell M, Davidson L. Service providers' views of psychiatric mutual support groups. J Community Psychol 2002; 30: 349-66.

30 Brown LD, Shepherd MD, Wituk SA, Meissen G. Introduction to the special issue on mental health self-help. Am J Community Psychol 2008; 42: 105-9.

31 Pistrang N, Barker C, Humphreys K. Mutual help groups for mental health problems: a review of effectiveness studies. Am J Community Psychol 2008; 42: 110-21.

32 De Shazer S. Keys to Solution in Brief Therapy. Norton, 1985.

33 De Shazer S. Clues: Investigating Solutions in Brief Therapy. Norton, 1988.
34 Bavelas J, De Jong P, Franklin C, Froerer A, Gingerick W, Kim J, et al. Solution Focused Therapy Treatment Manual for Working with Individuals (2nd version). Solution Focused Brief Therapy Association, 2013.

35 Minuchin S. Families and Family Therapy. Harvard University Press, 1974

36 Watzlawick P, Weakland J, Fisch R. Change: Principles of Problem Formation and Problem Resolution. Norton, 1974.

37 Selvini Palazzoli M, Boscolo L, Cecchin G, Prata G. Paradox and Counter Paradox: A New Model in the Therapy of the Family in Schizophrenia Transaction. Aronson, 1978.

38 Selvini MP, Boscolo L, Cecchin G, Prata G. Hypothesizing-circularityneutrality: three guidelines for the conductor of the session. Fam Process 1980; 19: 3-12.

39 Jones M. Social Psychiatry in Practice: The Idea of the Therapeutic Community. Penguin, 1968

40 Rapoport R. Community As Doctor: New Perspectives on a Therapeutic Community. Tavistock, 1960

41 Keenan S, Paget S. Service Standards for Therapeutic Communities (5th edn). Royal College of Psychiatrists' Research Unit, 2006 (http:// www.rcpsych.ac.uk/PDF/Service\%20Standards\%20for\%20Therapeutic\%20 Communities\%205th\%20Edition.pdf).

42 Kennard D. The therapeutic community as an adaptable treatment modality across different settings. Psychiatr Q 2004; 75: 295-307.

43 De Shazer S. Patterns of Brief Family Therapy: An Ecosystem Approach. Guilford, 1982.

44 Priebe S, Mccabe R. Therapeutic relationships in psychiatry: the basis of therapy or therapy in itself? Int Rev Psychiatry 2008; 20: 521-6.

45 Wampold BE, Budge SL. The 2011 Leona Tyler award address: the relationship - and its relationship to the common and specific factors of psychotherapy. Couns Psychol 2012; 40: 601-23.

46 Corrigan PW, Phelan SM. Social support and recovery in people with serious mental illnesses. Community Ment Health J 2004; 40: 513-23.

47 Topor A, Borg M, Mezzina R, Sells D, Marin I, Davidson L. Others: the role of family, friends and professionals in the recovery process. Am J Psychiatr Rehabil 2006; 9: 17-37.

48 Schon UK, Denhov A, Topor A. Social relationships as a decisive factor in recovering from severe mental illness. Int J Soc Psychiatry 2009; 55: 336-47.

49 Tew J, Ramon S, Slade M, Bird V, Melton J, Le Boutillier C. Social factors and recovery from mental health difficulties: a review of the evidence. $\mathrm{Br} J \mathrm{SOC}$ Work 2012; 42: 443-60.

50 Bengtsson-Tops A, Hansson L. Quantitative and qualitative aspects of the social network in schizophrenic patients living in the community. Relationship to sociodemographic characteristics and clinical factors and subjective quality of life. Int J Soc Psychiatry 2001; 47: 67-77.

51 Goldberg RW, Rollins AL, Lehman AF. Social network correlates among people with psychiatric disabilities. Psychiatr Rehabil J 2003; 26: 393-402.

52 MacDonald E, Sauer K, Howie L, Albiston D. What happens to social relationships in early psychosis? A phenomenological study of young people's experiences. J Ment Health 2005; 14: 129-43.

53 Horan WP, Subotnik KL, Snyder KS, Nuechterlein KH. Do recent-onset schizophrenia patients experience a 'social network crisis'? Psychiatry 2006; 69: 115-29.

54 Gayer-Anderson C, Morgan C. Social networks, support and early psychosis: a systematic review. Epidemiol Psychiatr Sci 2012; 26: 1-16.

55 Yanos PT, Rosenfield S, Horwitz AV. Negative and supportive social interactions and quality of life among persons diagnosed with severe mental illness. Community Ment Health J 2001; 37: 405-19.

56 Hooley JM. Expressed emotion and relapse of psychopathology. Annu Rev Clin Psychol 2007; 3: 329-52.

57 Cardenas V, Abel S, Bowie CR, Tiznado D, Depp CA, Patterson TL, et al. When functional capacity and real-world functioning converge: the role of self-efficacy. Schizophr Bull 2013; 39: 908-16.

58 Bingham CW, Sidorkin AM. No Education Without Relation. Lang, 2004.

59 World Health Organization. The Importance of Caregiver-Child Interactions for the Survival and Healthy Development of Young Children: A Review. WHO Department of Child and Adolescent Health and Development, 2004 (http:// whqlibdoc.who.int/publications/2004/924159134X.pdf).

60 Folgheraiter F. Relational social work: principles and practices. SOC POl SOC 2007; 6: $265-74$.

61 Holt-Lunstad J, Smith TB, Layton JB. Social relationships and mortality risk: a meta-analytic review. PLOS Med 2010; 7: e1000316.

62 Gilburt H, Rose D, Slade M. The importance of relationships in mental health care: a qualitative study of service users' experiences of psychiatric hospital admission in the UK. BMC Health Serv Res 2008; 8: 92. 